\title{
Effects of Full-size Panel Width on Cutting Yield of Wood-based Composites as Upholstery Furniture Frame Stocks
}

\begin{abstract}
Arif Caglar Konukcu, ${ }^{\mathrm{a}}$ and Jilei Zhang ${ }^{\mathrm{b}, *}$
In the competitive market, many furniture manufacturers are improving their process efficiency, eliminating unnecessary costs, and improving quality by using wood-based composite panels in frames. Currently, upholstery furniture frames are made by using over $70 \%$ wood-based composite panels, which causes material utilization to be the most important area of improvement. Many furniture manufacturers have realized that increased design and production efficiencies using woodbased panel products as their frame stocks combined with computer numerical control (CNC) technology is beneficial for the manufacturing process. However, manufacturers are continuously looking for alternatives to improve the bottom line of the manufacturing process, which includes optimization of the assumed panel width to maximize the cutting yield. In this case study, the effects of increasing the width of full-size wood-based composite panel products (1219-mm-wide $\times 2438$-mm-long) on the cutting yield of parts for two upholstered frame models were investigated using computer simulation software with an optimization capacity. The results of the simulation indicated that increasing the width of the full-size woodbased composite panel products to $1371 \mathrm{~mm}$ and $1524 \mathrm{~mm}$ could yield better material cutting yields compared with the 1219-mm-wide panel products.
\end{abstract}

Keywords: Wood-based composites; CNC; Yield; Optimization; Panel size; Upholstered furniture

Contact information: a: Department of Forest Industrial Engineering, Izmir Katip Celebi University, Izmir 35620, Turkey; b: Department of Sustainable Bioproducts, Mississippi State University, Mississippi State, MS 39762-5724, USA; *Corresponding author: jz27@msstate.edu

\section{INTRODUCTION}

Improving material utilization is a reoccurring interest of upholstered furniture manufacturers. Wood-based composite panels, such as oriented strand board (OSB) and plywood, are the most common raw materials used in the upholstered furniture industry as frame stocks. The American Plywood Association (APA) reported that $70 \%$ of upholstered furniture frame materials are wood-based composite panels (APA 2001). Therefore, improving the utilization yield of these wood-based composite panel products as furniture frame stocks has become the main focus of upholstered furniture manufacturers in an effort to continuously improve the bottom line.

The technology for forest products manufacturing has drastically changed as the use of computers became an essential part of product evaluation, process control, and analysis (Youngs 1994). Computer numerical control (CNC) technology appeared in woodworking industries in the 1980s, but many companies purchased their first CNC machines in the early 1990s (Wiedenbeck and Parsons 2010). The CNC machining technology has the advantage of producing a variety of curved parts for manufacturers. 
These machines produce accurate parts with an adequate surface quality in upholstered furniture manufacturing (Annamalai 2003). Wiedenbeck and Parsons (2010) reported that $41 \%$ of their survey respondents used CNC routers. The CNC router technology helps manufacturers to minimize machining errors, such as tool breakage and tool deflection (Park and Kim 1998).

Wood-based composite panels and CNC routers allow upholstered furniture manufacturers to save time and achieve a remarkably higher yield. For instance, a frame for a piece of furniture can be cut from a single wood-based composite panel sheet in minutes by $\mathrm{CNC}$ routers. This process would not be economically possible if the manufacturers used hardwood lumber because wood-based composite panels give manufacturers the opportunity to optimize cutting patterns. Wood-based composite panels offer several critical advantages, including labor savings, raw material cost savings, and higher material utilization yields through CNC technology (APA 1997b). It has been reported that the use of OSB and plywood in upholstered furniture frame construction has grown from $10 \%$ of the total market in 1992 to $41 \%$ (APA 2001). This shows the importance of wood-based composite panels in the current furniture industry.

The CNC router technology allows manufacturers to increase design production efficiency by using wood-based composite panels (Konukcu 2014). Hence, upholstered furniture manufacturers have a high yield productivity and minimum manufacturing cost because CNC equipment can eliminate many manual operations (APA 1997a). Upholstered furniture manufacturers using wood-based composite panels instead of hardwood lumber as their furniture frame stocks achieve a higher material yield and reduce the assembly costs. It has been reported that Rowe, an upholstered furniture manufacturer, has continued to deliver and improve its product quality by using CNC technology to cut plywood for frame parts (APA 1997b). The company reported its manufacturing efficiencies with CNC equipment for cutting plywood panel products, and has an impressive $87 \%$ to $90 \%$ material utilization yield, versus only $48 \%$ to $50 \%$ with its previous hardwood lumber usage. According to APA (1997a), Bassett, another upholstered furniture manufacturer, has converted from hardwood lumber to $100 \%$ plywood frames. The company consistently produces a cutting yield of up to $90 \%$. Also, the manufacturer was able to control costs, improve manufacturing efficiencies, and deliver a more solid product to the market. Previous reports and studies have shown that high material cutting yields allow manufacturers to minimize material waste and reduce cost, which benefits the environment. Several factors, such as the cutting pattern layout design, full-panel size, and shape of the frame parts, can affect the panel-cutting yield when using CNC router technology.

Therefore, the main objective of this study was to investigate the effect of these factors on the cutting yield of CNC routers with full-size wood-based composite panel products by using computer simulation software that has a part cutting pattern layout optimization capacity. The specific objectives were to investigate the effect on the cutting yield of the full-panel sizes of wood-based composites, cut-frame batch, and frame part shape and size. It is believed that the results from this study will provide valuable information to both upholstery furniture manufacturers and panel product suppliers for a better understanding of the major factors that affect the material-cutting yield, and therefore allow them to continue to participate in efforts to improve the material yield. 


\section{EXPERIMENTAL}

\section{Materials}

Two upholstered furniture frame models were selected for this study. Figures 1 and 2 show the detailed 3D AutoCAD (Albany Industries, New Albany, Mississippi, USA) drawings of the two models, Models I and II. A Mississippi furniture manufacturer provided the frame part data files. The two frame models had the parts cut mainly from solid wood lumber and wood-based composite panels.

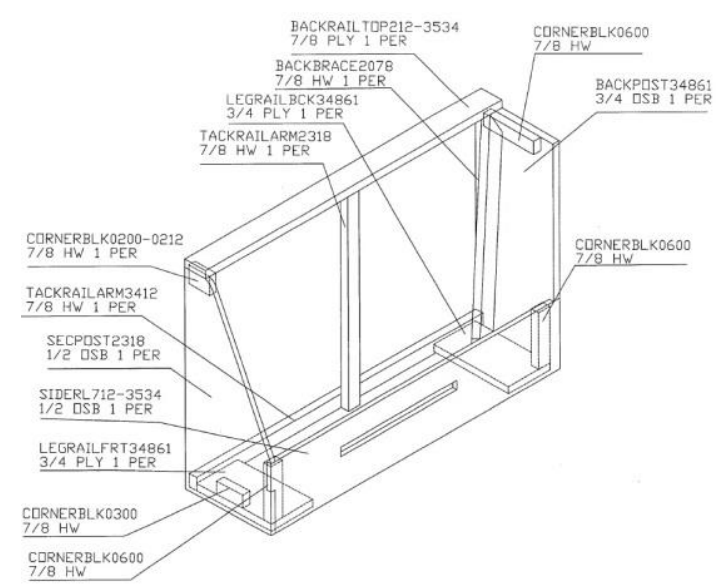

(a)

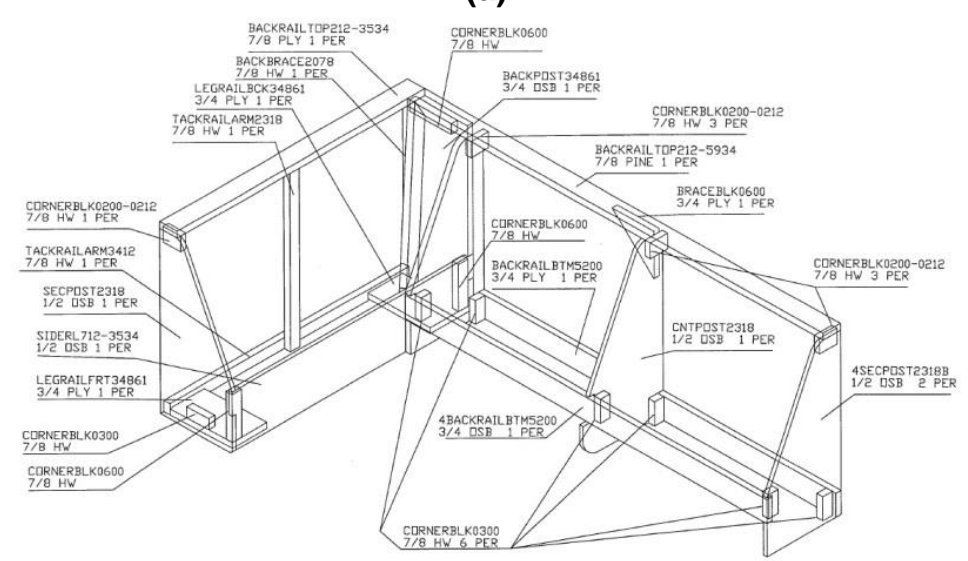

(b)

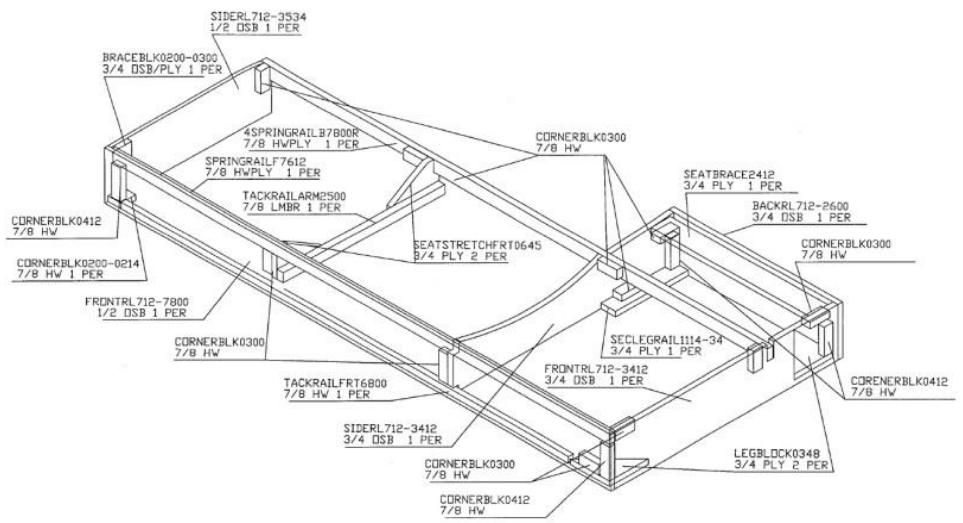

(c)

Fig. 1. 3D AutoCAD drawings showing all of the frame parts and detailed construction in Model I, including (a) arm frame, (b) arm and back frame, and (c) seat frame 


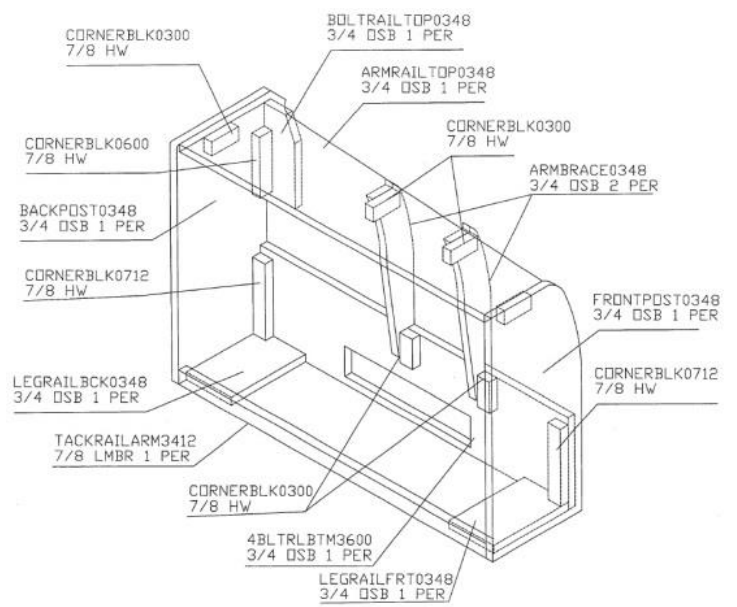

(a)

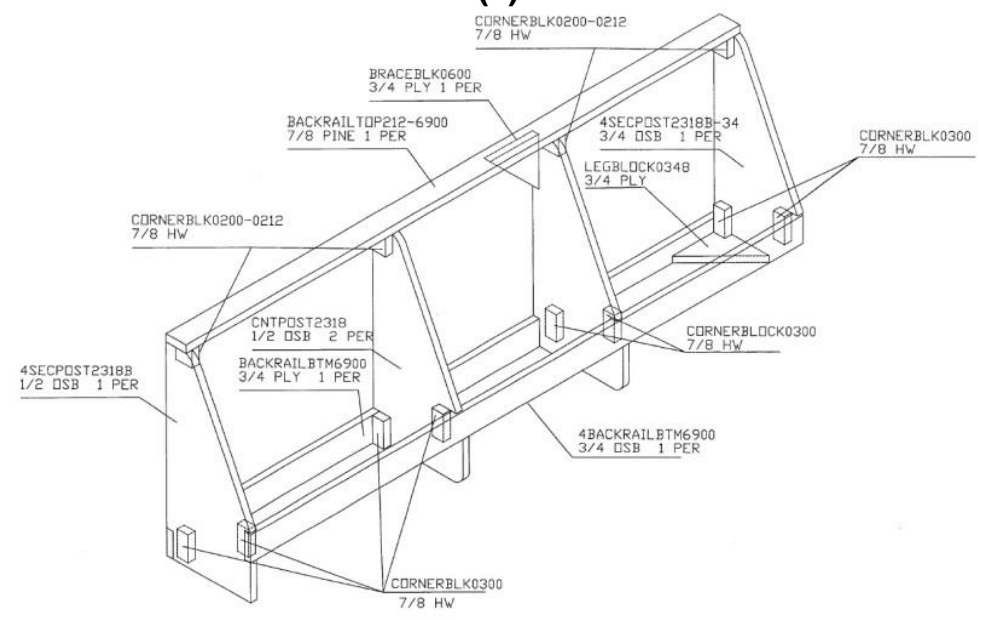

(b)

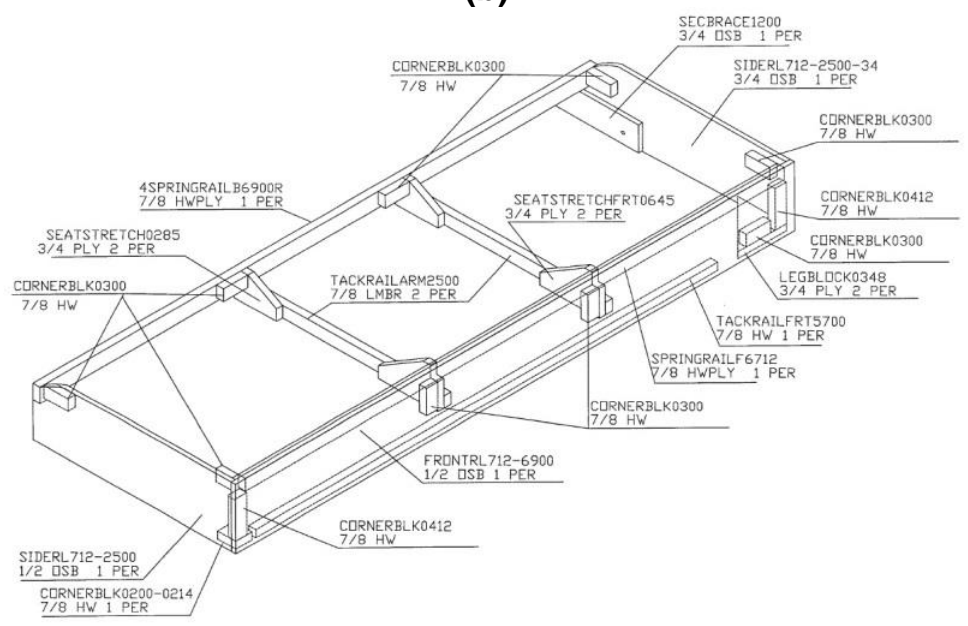

(c)

Fig. 2. 3D AutoCAD drawings showing all of the frame parts and detailed construction in Model II, including (a) arm frame, (b) back frame, and (c) seat frame

Table 1 summarizes the number of frame parts with the corresponding volume and percentage for each of the four material types used in the frame construction, including solid wood lumber. The volume percentages of the wood-based composite panels for 
Models I and II were $75.3 \%$ and $80.3 \%$, respectively. Model I had 22 of 65 parts cut from wood-based composite panels, while for Model II it was 26 of 66 parts. Figures 3 and 4 are AutoCAD drawings that show the shapes of all of the frame parts for Models I and II, respectively. Table 2 summarizes the quantity, size, and material type of all of the frame parts cut from the three different types of wood-based composite panel products for Models I and II.

Table 1. Volumes and Percentages of the Different Frame Materials Used in Models I and II

\begin{tabular}{|c|c|c|c|c|}
\hline \multirow{2}{*}{ Model } & Material Type & $\begin{array}{c}\text { Number of } \\
\text { Frame Parts }\end{array}$ & Volume $\left(\mathrm{cm}^{3}\right)$ & $\begin{array}{c}\text { Percentage } \\
(\%)\end{array}$ \\
\hline \multirow{4}{*}{ I } & Solid wood & 43 & 12318.1 & 24.7 \\
\cline { 2 - 5 } & $12-\mathrm{mm}$-thick OSB & 6 & 14266.5 & 28.6 \\
\cline { 2 - 5 } & $19-\mathrm{mm}$-thick OSB & 6 & 16957.0 & 34.1 \\
\cline { 2 - 5 } & $19-\mathrm{mm}$-thick plywood & 10 & 6271.0 & 12.6 \\
\hline \multirow{4}{*}{ II } & Solid wood & 40 & 10328.0 & 19.7 \\
\cline { 2 - 5 } & $12-\mathrm{mm}$-thick OSB & 5 & 11937.6 & 22.8 \\
\cline { 2 - 5 } & $19-\mathrm{mm}$-thick OSB & 11 & 24158.1 & 46.1 \\
\cline { 2 - 5 } & $19-\mathrm{mm}$-thick plywood & 10 & 6015.0 & 11.4 \\
\hline
\end{tabular}

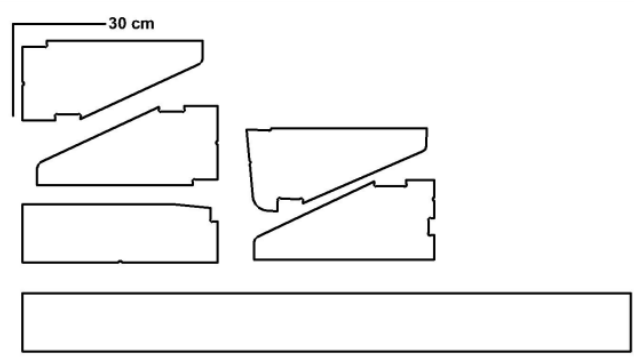

(a)

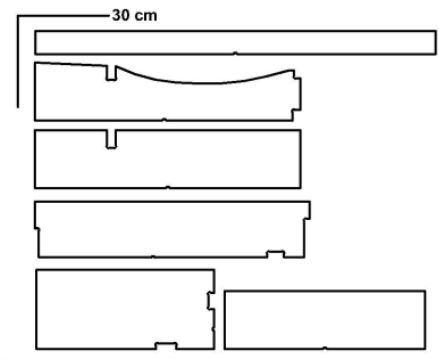

(b)

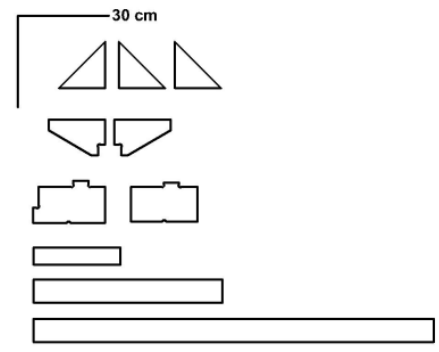

(c)

Fig. 3. 2D AutoCAD drawings showing the shapes and sizes of all of the frame members in Model I, including (a) six frame members cut from 12-mm-thick OSB; (b) six frame members cut from 19-mm-thick OSB; and (c) 10 frame members cut from 19-mm-thick plywood 


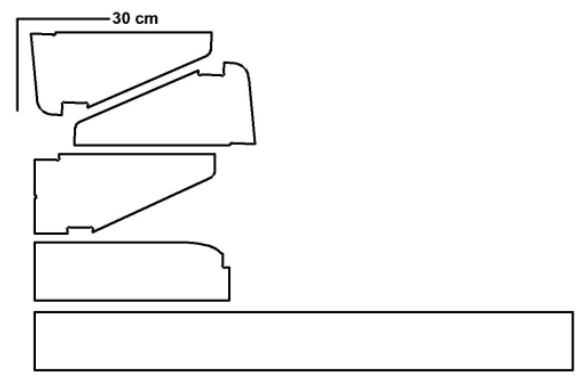

(a)

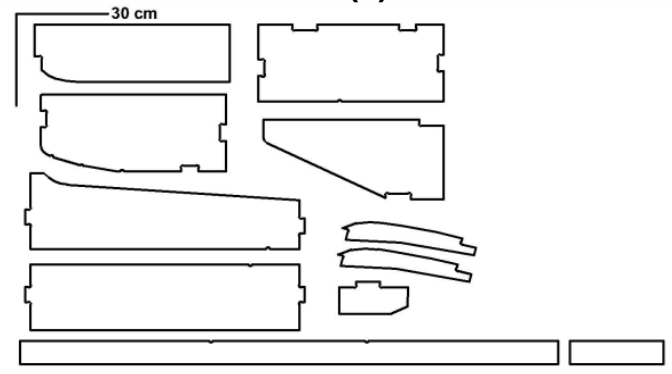

(b)

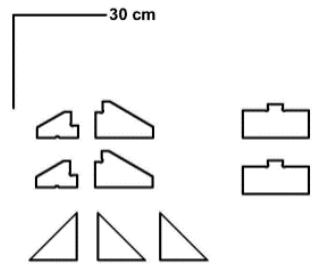

(c)

Fig. 4. 2D AutoCAD drawings showing the shapes and sizes of all of the frame members for Model II, including (a) five frame members cut from 12-mm-thick OSB; (b) 11 frame members cut from 19-mm-thick OSB; and (c) 10 frame members cut from 19-mm-thick plywood

\section{Methods}

The software used for the optimization of the material cutting yield in this study was Plataine Version 7.0 Total Production Optimization Wood Optimizer (Waltham, MA, USA). This software provides upholstered furniture manufacturers with an integrated solution for dynamic nesting and cut-path optimization. The general steps for running the program included first preparing all of the cutting parts for the two frame models on AutoCAD, importing the AutoCAD part layouts into the optimization software, and running the program after entering other parameters, such as the planned number of furniture frames to run and number of full panel sizes to be evaluated.

A total of 180 simulation runs were performed in this study based on a $2 \times 3 \times 3 \times$ 10 factorial experiment design to evaluate the effect of four factors on the panel cutting yield. The four factors were the upholstered furniture frame model (Models I and II), 2438mm long wood-based composite panel width (1219 mm, $1371 \mathrm{~mm}$, and $1524 \mathrm{~mm})$, woodbased composite panel type (12-mm-thick OSB, 19-mm-thick OSB, and 19-mm-thick plywood), and batch size of the furniture frame runs $(5,10,15,20,25,30,35,40,45$, and $50)$. 
Table 2. Parts in Models I and II, Corresponding Dimensions, and Material Types Used

\begin{tabular}{|c|c|c|c|c|c|}
\hline \multirow{2}{*}{ Model } & \multirow{2}{*}{ Part } & \multirow{2}{*}{ Quantity } & \multicolumn{2}{|c|}{ Part Dimension $(\mathrm{cm})$} & \multirow{2}{*}{ Material Type } \\
\hline & & & Width & Length & \\
\hline \multirow{19}{*}{1} & Side post & 2 & 26.04 & 58.75 & \multirow{5}{*}{ 12-mm-thick OSB } \\
\hline & Center post & 1 & 28.27 & 58.75 & \\
\hline & Side rail & 1 & 19.05 & 63.50 & \\
\hline & Front rail & 1 & 19.05 & 198.12 & \\
\hline & Side post & 1 & 26.04 & 58.75 & \\
\hline & Back rail bottom & 1 & 7.62 & 132.08 & \multirow{6}{*}{ 19-mm-thick OSB } \\
\hline & Side rail & 1 & 19.05 & 87.63 & \\
\hline & Back rail & 1 & 19.05 & 66.04 & \\
\hline & Front rail & 1 & 19.05 & 87.63 & \\
\hline & Side rail & 1 & 19.05 & 90.81 & \\
\hline & Back post & 1 & 26.04 & 58.75 & \\
\hline & Leg block & 2 & 15.24 & 15.24 & \multirow{8}{*}{ 19-mm-thick plywood } \\
\hline & Seat stretch front & 2 & 11.76 & 18.57 & \\
\hline & Back rail bottom & 1 & 7.62 & 132.08 & \\
\hline & Brace block & 1 & 15.24 & 15.24 & \\
\hline & Side leg rail & 1 & 5.72 & 28.58 & \\
\hline & Seat brace & 1 & 7.62 & 62.23 & \\
\hline & Leg rail back & 1 & 13.97 & 23.83 & \\
\hline & Leg rail front & 1 & 12.70 & 14.30 & \\
\hline \multirow{20}{*}{ II } & Center post & 2 & 28.27 & 58.75 & \multirow{4}{*}{ 12-mm-thick OSB } \\
\hline & Side post & 1 & 26.04 & 58.75 & \\
\hline & Side rail & 1 & 19.05 & 63.50 & \\
\hline & Front rail & 1 & 19.05 & 175.26 & \\
\hline & Arm brace & 2 & 9.53 & 43.82 & \multirow{10}{*}{ 19-mm-thick OSB } \\
\hline & Back rail bottom & 1 & 7.62 & 175.26 & \\
\hline & Side post & 1 & 26.04 & 58.75 & \\
\hline & Side rail & 1 & 19.05 & 63.50 & \\
\hline & Side brace & 1 & 7.62 & 30.48 & \\
\hline & Front post & 1 & 25.40 & 60.33 & \\
\hline & Back post & 1 & 25.40 & 60.33 & \\
\hline & Arm rail top & 1 & 24.77 & 91.44 & \\
\hline & Bolt rail bottom & 1 & 21.59 & 91.44 & \\
\hline & Bolt rail top & 1 & 10.64 & 22.23 & \\
\hline & Leg block & 2 & 15.24 & 15.24 & \multirow{6}{*}{ 19-mm-thick plywood } \\
\hline & Seat stretch front & 2 & 11.76 & 18.57 & \\
\hline & Seat stretch & 2 & 8.59 & 13.34 & \\
\hline & Leg rail block & 2 & 21.29 & 10.80 & \\
\hline & Back rail bottom & 1 & 7.62 & 175.26 & \\
\hline & Brace block & 1 & 15.24 & 15.24 & \\
\hline
\end{tabular}




\section{RESULTS AND DISCUSSION}

Tables 3 and 4 summarize the simulated panel cutting yields of the three woodbased composites for Models I and II, respectively. In general, Table 3 shows that the cutting yield of the full-size 2438-mm-long panels with the commonly seen width of 1219 $\mathrm{mm}$ for Model I ranged from $78.72 \%$ to $86.17 \%$ for the 12 -mm-thick OSB panels, $80.16 \%$ to $84.12 \%$ for the 19 -mm-thick OSB panels, and $71.39 \%$ to $76.87 \%$ for the 19 -mm-thick plywood panels. Table 4 shows that the cutting yield of the full-size 2438 - $\mathrm{mm}$-long panels with the commonly seen width of $1219 \mathrm{~mm}$ for Model II ranged from $78.23 \%$ to $88.04 \%$ for the 12 -mm-thick OSB panels, $81.34 \%$ to $84.53 \%$ for the 19 -mm-thick OSB panels, and $58.29 \%$ to $68.75 \%$ for the 19 -mm-thick plywood panels.

Table 3. Summary of the Panel Cutting Yields Generated from the Running Simulation for the Three Wood-based Composite Panels for Model I

\begin{tabular}{|c|c|c|c|c|c|c|c|c|c|c|}
\hline \multirow{3}{*}{$\begin{array}{l}\text { Panel } \\
\text { Width } \\
(\mathrm{mm})\end{array}$} & \multirow{3}{*}{$\begin{array}{c}\text { Frame } \\
\text { Batch } \\
\text { Size }\end{array}$} & \multicolumn{9}{|c|}{ Material Type } \\
\hline & & \multicolumn{3}{|c|}{ 12-mm-thick OSB } & \multicolumn{3}{|c|}{ 19-mm-thick OSB } & \multicolumn{3}{|c|}{ 19-mm-thick plywood } \\
\hline & & $\begin{array}{l}\text { Part } \\
\text { Area } \\
\left(\mathrm{m}^{2}\right)\end{array}$ & $\begin{array}{c}\text { Panel } \\
\text { Area } \\
\left(\mathrm{m}^{2}\right)\end{array}$ & $\begin{array}{c}\text { Yield } \\
(\%)\end{array}$ & $\begin{array}{l}\text { Part } \\
\text { Area } \\
\left(\mathrm{m}^{2}\right)\end{array}$ & $\begin{array}{c}\text { Panel } \\
\text { Area } \\
\left(\mathrm{m}^{2}\right)\end{array}$ & $\begin{array}{c}\text { Yield } \\
(\%)\end{array}$ & $\begin{array}{l}\text { Part } \\
\text { Area } \\
\left(\mathrm{m}^{2}\right)\end{array}$ & $\begin{array}{l}\text { Panel } \\
\text { Area } \\
\left(\mathrm{m}^{2}\right)\end{array}$ & $\begin{array}{c}\text { Yield } \\
\text { (\%) }\end{array}$ \\
\hline \multirow{10}{*}{1219} & 5 & 4.68 & 5.95 & 78.72 & 4.84 & 5.95 & 81.34 & 2.17 & 2.97 & 73.15 \\
\hline & 10 & 10.19 & 11.89 & 85.70 & 9.75 & 11.89 & 81.97 & 4.57 & 5.95 & 76.87 \\
\hline & 15 & 15.24 & 17.84 & 85.44 & 14.30 & 17.84 & 80.16 & 4.24 & 5.95 & 71.39 \\
\hline & 20 & 20.36 & 23.78 & 85.59 & 17.51 & 20.81 & 84.12 & 6.72 & 8.92 & 75.40 \\
\hline & 25 & 24.80 & 29.73 & 83.41 & 22.03 & 26.76 & 82.35 & 9.02 & 11.89 & 75.86 \\
\hline & 30 & 29.66 & 35.67 & 83.13 & 26.37 & 32.70 & 80.65 & 8.96 & 11.89 & 75.38 \\
\hline & 35 & 33.30 & 38.65 & 86.17 & 29.64 & 35.67 & 83.08 & 11.20 & 14.86 & 75.35 \\
\hline & 40 & 38.23 & 44.59 & 85.74 & 34.60 & 41.62 & 83.13 & 13.42 & 17.84 & 75.26 \\
\hline & 45 & 43.32 & 50.54 & 85.72 & 39.20 & 47.57 & 82.42 & 13.38 & 17.84 & 75.03 \\
\hline & 50 & 48.16 & 56.49 & 85.27 & 41.92 & 50.54 & 82.95 & 15.76 & 20.81 & 75.72 \\
\hline \multirow{10}{*}{1371} & 5 & 5.64 & 6.69 & 84.29 & 5.67 & 6.69 & 84.77 & 2.41 & 3.34 & 71.95 \\
\hline & 10 & 11.66 & 13.38 & 87.15 & 8.39 & 10.03 & 83.57 & 5.12 & 6.69 & 76.60 \\
\hline & 15 & 14.04 & 16.72 & 83.96 & 14.17 & 16.72 & 84.76 & 5.02 & 6.69 & 75.01 \\
\hline & 20 & 20.23 & 23.41 & 86.43 & 16.77 & 20.07 & 83.57 & 7.64 & 10.03 & 76.11 \\
\hline & 25 & 25.57 & 30.10 & 84.96 & 22.43 & 26.76 & 83.82 & 7.58 & 10.03 & 75.51 \\
\hline & 30 & 28.86 & 33.45 & 86.28 & 25.16 & 30.10 & 83.57 & 10.01 & 13.38 & 74.85 \\
\hline & 35 & 34.15 & 40.13 & 85.09 & 30.67 & 36.79 & 83.37 & 9.91 & 13.38 & 74.04 \\
\hline & 40 & 37.44 & 43.48 & 86.12 & 34.10 & 40.13 & 84.96 & 12.71 & 16.72 & 76.03 \\
\hline & 45 & 43.08 & 50.17 & 85.87 & 39.15 & 46.82 & 83.61 & 14.96 & 20.07 & 74.56 \\
\hline & 50 & 49.10 & 56.86 & 86.36 & 41.93 & 50.17 & 83.57 & 15.07 & 20.07 & 75.09 \\
\hline \multirow{10}{*}{1524} & 5 & 6.29 & 7.43 & 84.61 & 6.01 & 7.43 & 80.86 & 2.60 & 3.72 & 70.03 \\
\hline & 10 & 9.36 & 11.15 & 83.96 & 9.49 & 11.15 & 85.12 & 3.77 & 7.43 & 50.71 \\
\hline & 15 & 15.98 & 18.58 & 85.99 & 12.58 & 14.86 & 84.61 & 5.61 & 7.43 & 75.45 \\
\hline & 20 & 18.72 & 22.30 & 83.96 & 18.90 & 22.30 & 84.78 & 8.80 & 11.15 & 78.95 \\
\hline & 25 & 25.67 & 29.73 & 86.35 & 22.03 & 26.01 & 84.67 & 8.35 & 11.15 & 74.87 \\
\hline & 30 & 28.75 & 33.45 & 85.96 & 25.15 & 29.73 & 84.61 & 11.22 & 14.86 & 75.45 \\
\hline & 35 & 35.18 & 40.88 & 86.07 & 30.90 & 37.16 & 83.15 & 11.18 & 14.86 & 75.21 \\
\hline & 40 & 38.31 & 44.59 & 85.90 & 34.33 & 40.88 & 83.98 & 13.68 & 18.58 & 73.60 \\
\hline & 45 & 44.03 & 52.03 & 84.63 & 39.79 & 48.31 & 82.36 & 13.82 & 18.58 & 74.36 \\
\hline & 50 & 47.88 & 55.74 & 85.90 & 44.06 & 52.03 & 84.68 & 16.80 & 22.30 & 75.34 \\
\hline
\end{tabular}


Table 4. Summary of the Panel Cutting Yields Generated from the Running Simulation for the Three Wood-based Composite Panels for Model II

\begin{tabular}{|c|c|c|c|c|c|c|c|c|c|c|}
\hline \multirow{3}{*}{$\begin{array}{l}\text { Panel } \\
\text { Width } \\
(\mathrm{mm})\end{array}$} & \multirow{3}{*}{$\begin{array}{c}\text { Frame } \\
\text { Batch } \\
\text { Size }\end{array}$} & \multicolumn{9}{|c|}{ Material Type } \\
\hline & & \multicolumn{3}{|c|}{ 12-mm-thick OSB } & \multicolumn{3}{|c|}{ 19-mm-thick OSB } & \multicolumn{3}{|c|}{ 19-mm-thick plywood } \\
\hline & & $\begin{array}{l}\text { Part } \\
\text { Area } \\
\left(\mathrm{m}^{2}\right)\end{array}$ & $\begin{array}{c}\text { Panel } \\
\text { Area } \\
\left(\mathrm{m}^{2}\right)\end{array}$ & $\begin{array}{c}\text { Yield } \\
(\%)\end{array}$ & $\begin{array}{l}\text { Part } \\
\text { Area } \\
\left(\mathrm{m}^{2}\right)\end{array}$ & $\begin{array}{c}\text { Panel } \\
\text { Area } \\
\left(\mathrm{m}^{2}\right)\end{array}$ & $\begin{array}{c}\text { Yield } \\
(\%)\end{array}$ & $\begin{array}{l}\text { Part } \\
\text { Area } \\
\left(\mathrm{m}^{2}\right)\end{array}$ & $\begin{array}{l}\text { Panel } \\
\text { Area } \\
\left(\mathrm{m}^{2}\right)\end{array}$ & $\begin{array}{c}\text { Yield } \\
\text { (\%) }\end{array}$ \\
\hline \multirow{10}{*}{1219} & 5 & 4.81 & 5.95 & 80.85 & 7.25 & 8.92 & 81.34 & 1.75 & 2.97 & 59.02 \\
\hline & 10 & 9.30 & 11.89 & 78.23 & 12.38 & 14.86 & 83.29 & 3.89 & 5.95 & 65.42 \\
\hline & 15 & 12.60 & 14.86 & 84.77 & 17.44 & 20.81 & 83.80 & 4.06 & 5.95 & 68.33 \\
\hline & 20 & 15.49 & 17.84 & 86.82 & 22.57 & 26.76 & 84.34 & 6.10 & 8.92 & 68.37 \\
\hline & 25 & 20.77 & 23.78 & 87.34 & 27.60 & 32.70 & 84.39 & 6.93 & 11.89 & 58.29 \\
\hline & 30 & 23.23 & 26.76 & 86.82 & 32.67 & 38.65 & 84.53 & 8.18 & 11.89 & 68.75 \\
\hline & 35 & 28.28 & 32.70 & 86.49 & 39.70 & 47.57 & 83.46 & 9.73 & 14.86 & 65.49 \\
\hline & 40 & 31.28 & 35.67 & 87.68 & 44.61 & 53.51 & 83.37 & 10.16 & 14.86 & 68.34 \\
\hline & 45 & 36.43 & 41.62 & 87.52 & 49.86 & 59.46 & 83.86 & 12.13 & 17.84 & 68.02 \\
\hline & 50 & 41.88 & 47.57 & 88.04 & 55.06 & 65.40 & 84.19 & 13.76 & 20.81 & 66.12 \\
\hline \multirow{10}{*}{1371} & 5 & 5.56 & 6.69 & 83.10 & 5.39 & 6.69 & 80.54 & 1.75 & 3.34 & 52.42 \\
\hline & 10 & 8.57 & 10.03 & 85.40 & 11.06 & 13.38 & 82.69 & 4.33 & 6.69 & 64.74 \\
\hline & 15 & 11.61 & 13.38 & 86.82 & 17.01 & 20.07 & 84.75 & 4.46 & 6.69 & 66.73 \\
\hline & 20 & 17.42 & 20.07 & 86.81 & 22.77 & 26.76 & 85.11 & 6.31 & 10.03 & 62.86 \\
\hline & 25 & 20.37 & 23.41 & 87.00 & 28.29 & 33.45 & 84.58 & 6.93 & 10.03 & 69.04 \\
\hline & 30 & 23.23 & 26.76 & 86.82 & 33.85 & 40.13 & 84.33 & 9.05 & 13.38 & 67.65 \\
\hline & 35 & 29.38 & 33.45 & 87.84 & 39.13 & 46.82 & 83.58 & 9.34 & 13.38 & 69.80 \\
\hline & 40 & 32.09 & 36.79 & 87.22 & 44.46 & 53.51 & 83.09 & 11.09 & 16.72 & 66.29 \\
\hline & 45 & 34.84 & 40.13 & 86.82 & 50.39 & 60.20 & 83.70 & 11.43 & 16.72 & 68.34 \\
\hline & 50 & 40.99 & 46.82 & 87.55 & 53.87 & 63.55 & 84.78 & 13.47 & 20.07 & 67.12 \\
\hline \multirow{10}{*}{1524} & 5 & 5.88 & 7.43 & 79.18 & 6.30 & 7.43 & 84.83 & 1.75 & 3.72 & 47.16 \\
\hline & 10 & 9.40 & 11.15 & 84.35 & 12.58 & 14.86 & 84.64 & 2.54 & 3.72 & 68.34 \\
\hline & 15 & 12.67 & 14.86 & 85.23 & 18.22 & 22.30 & 81.73 & 5.10 & 7.43 & 68.63 \\
\hline & 20 & 15.49 & 18.58 & 83.35 & 22.06 & 26.01 & 84.79 & 5.08 & 7.43 & 68.34 \\
\hline & 25 & 21.29 & 26.01 & 81.83 & 28.27 & 33.45 & 84.53 & 7.58 & 11.15 & 67.99 \\
\hline & 30 & 25.48 & 29.73 & 85.70 & 34.13 & 40.88 & 83.49 & 7.62 & 11.15 & 68.34 \\
\hline & 35 & 27.73 & 33.45 & 82.91 & 37.71 & 44.59 & 84.57 & 9.95 & 14.86 & 66.94 \\
\hline & 40 & 30.97 & 37.16 & 83.35 & 44.00 & 52.03 & 84.58 & 10.16 & 14.86 & 68.34 \\
\hline & 45 & 37.24 & 44.59 & 83.51 & 50.05 & 59.46 & 84.18 & 12.42 & 18.58 & 66.83 \\
\hline & 50 & 39.99 & 48.31 & 82.78 & 56.41 & 66.89 & 84.33 & 12.70 & 18.58 & 68.34 \\
\hline
\end{tabular}

Figure 5 shows the panel cutting yield differences between the 1371-mm- and 1219-mm-wide 12-mm-thick OSB panels and 1524-mm- and 1219-mm-wide 12-mm-thick OSB panels for Models I and II. There was a potential material cutting yield increase by altering the full-size panel width. Specifically, using 1371-mm-wide panels tended to have a better yield compared with the 1524-mm-wide panels, especially for Model II. The Model I frame had most of its yield difference points above 0\% (Fig. 5a), and the highest yield differences were $5.57 \%$ and $3.15 \%$ for frame batch sizes 5 and 30, respectively. The Model II frame had its most yield difference points above $0 \%$, i.e., six of 10 , and there were four negative points (Fig. 5b). These results also indicated that the frame batch size $(5,10,20$, 25 , and 30) can affect the material cutting yield and yield better overall material savings if both frame models are produced simultaneously. 


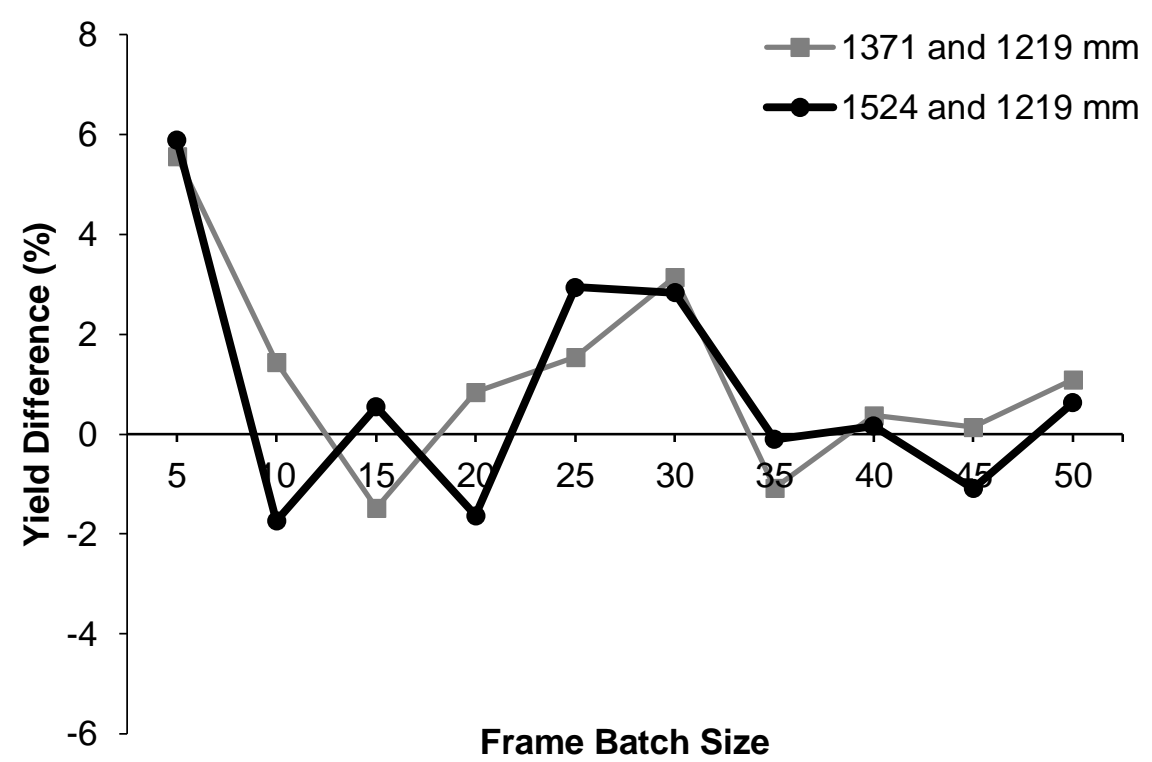

(a)

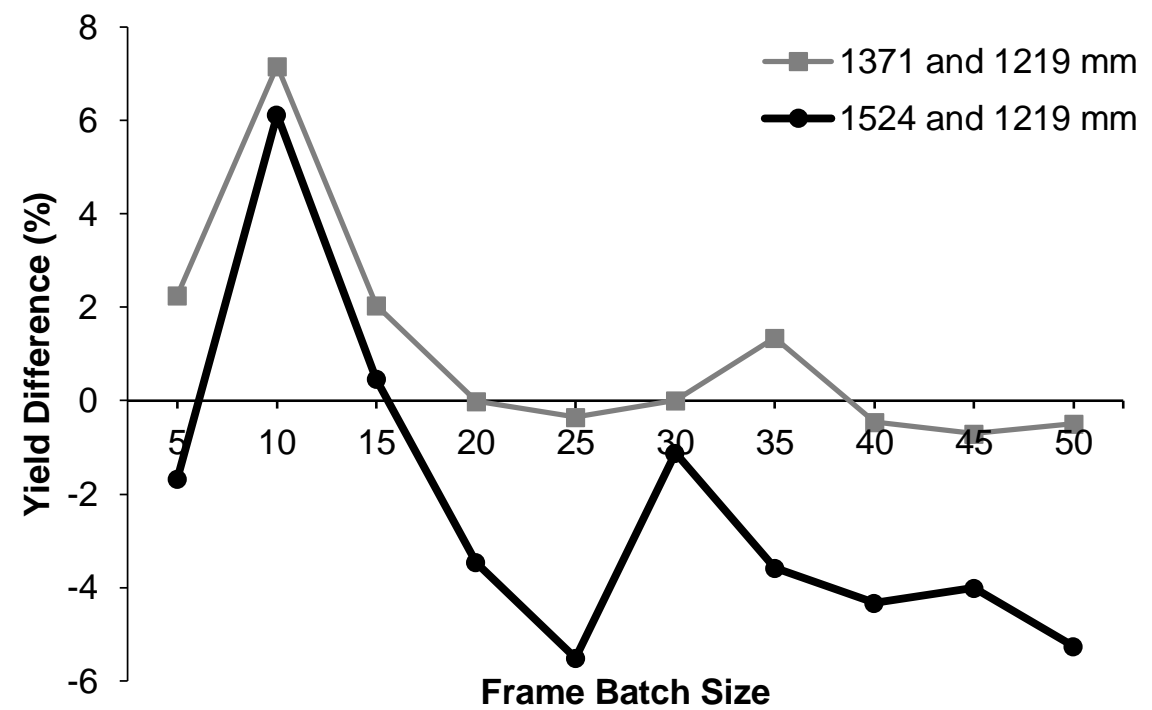

(b)

Fig. 5. Yield differences between the 1371-mm and 1219-mm-wide 12-mm-thick OSB panels and 1524-mm and 1219-mm-wide 12-mm-thick OSB panels for (a) Models I and (b) II, respectively

In the case of the 1524-mm-wide panels for Model I (Fig. 5a), there were increases in the yield differences in the frame batch sizes 5, 15, 25, 30, 40, and 50, and the highest yield difference of $5.89 \%$ occurred with the frame batch size 5. Model II had only two yield difference points above $0 \%$, i.e., for frame batch sizes 10 and 15. If running two frame models simultaneously, frame batch sizes 5, 10, 15, and 30 result in material cutting yields that are better overall.

Figure 6 illustrates the panel cutting yield differences between the 1371-mm- and 1219-mm-wide 19-mm-thick OSB panels and 1524-mm- and 1219-mm-wide 19-mm-thick OSB panels for Models I and II. In general, altering the full-size panel width from 1219 $\mathrm{mm}$ to $1371 \mathrm{~mm}$ and $1524 \mathrm{~mm}$ resulted in better yields for Model I because almost all of 
the yield difference points were above 0\% (Fig. 6a). For Model II (Fig. 6b), altering the full-size panel width from $1219 \mathrm{~mm}$ to $1371 \mathrm{~mm}$ resulted in five out of 10 yield difference points being above $0 \%$, while altering the full-size panel width from $1219 \mathrm{~mm}$ to $1524 \mathrm{~mm}$ resulted in eight out of 10 yield difference points being above $0 \%$. In general, these yield differences above $0 \%$ were less than those for Model I. These results also implied that the frame model difference, i.e., the differences in the number of parts in a frame, part shapes, and part dimensions, could also affect the material cutting yield differences.

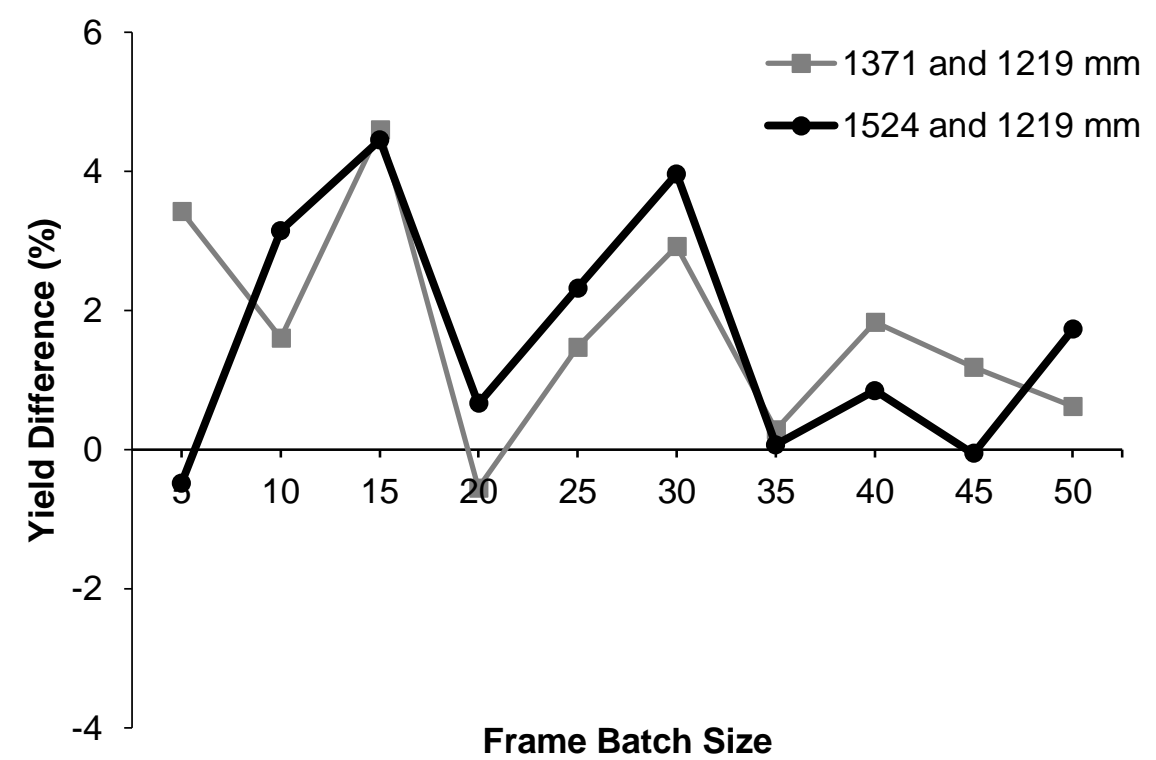

(a)

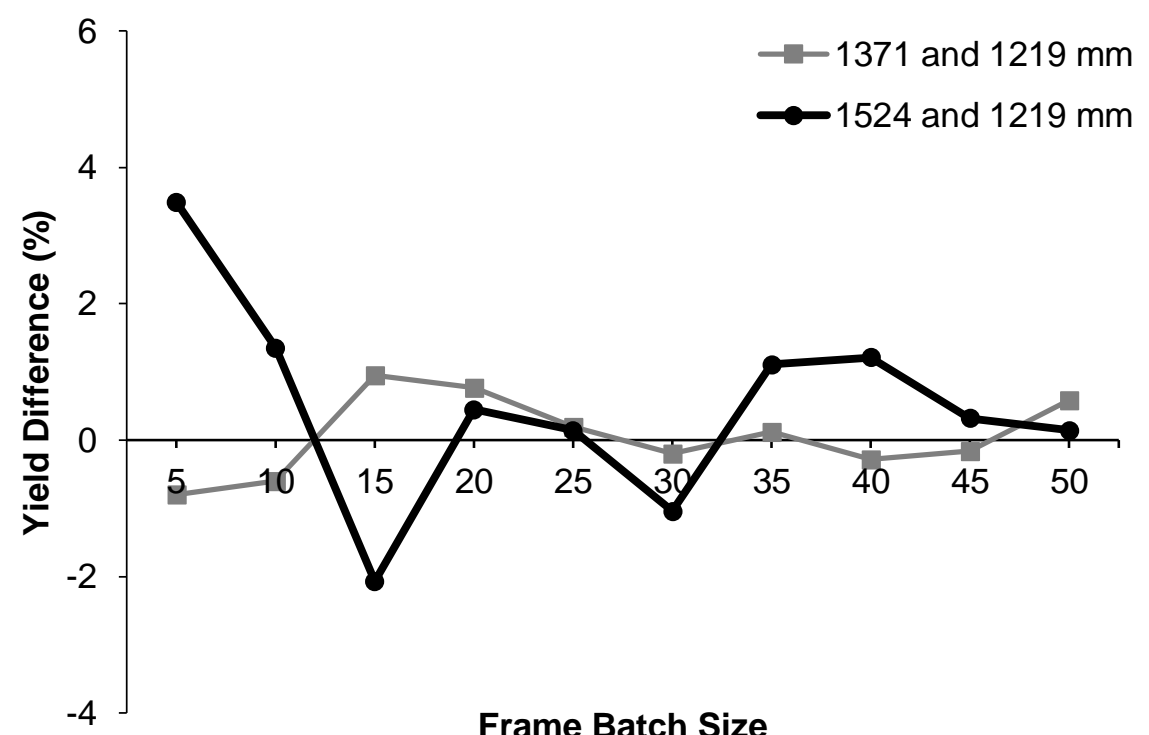

(b)

Fig. 6. Yield differences between the 1371-mm and 1219-mm-wide 19-mm-thick OSB panels and 1524-mm and 1219-mm-wide 19-mm-thick OSB panels for (a) Models I and (b) II, respectively

Figure 7 illustrates the panel cutting yield differences between the 1371-mm- and 1219-mm-wide 19-mm-thick plywood panels and 1524-mm- and 1219-mm-wide 19-mmthick plywood panels for Models I and II. In general, the yield difference points above 0\% 
in Fig. 7 were less than those in Figs. 5 and 6. This result implied that the frame part dimensions can affect the yield difference, i.e., small parts (Figs. 3c and 4c) result in lower yield differences than larger parts (Figs. $3 a$ and $3 b$, and Figs. 4a and 4b).

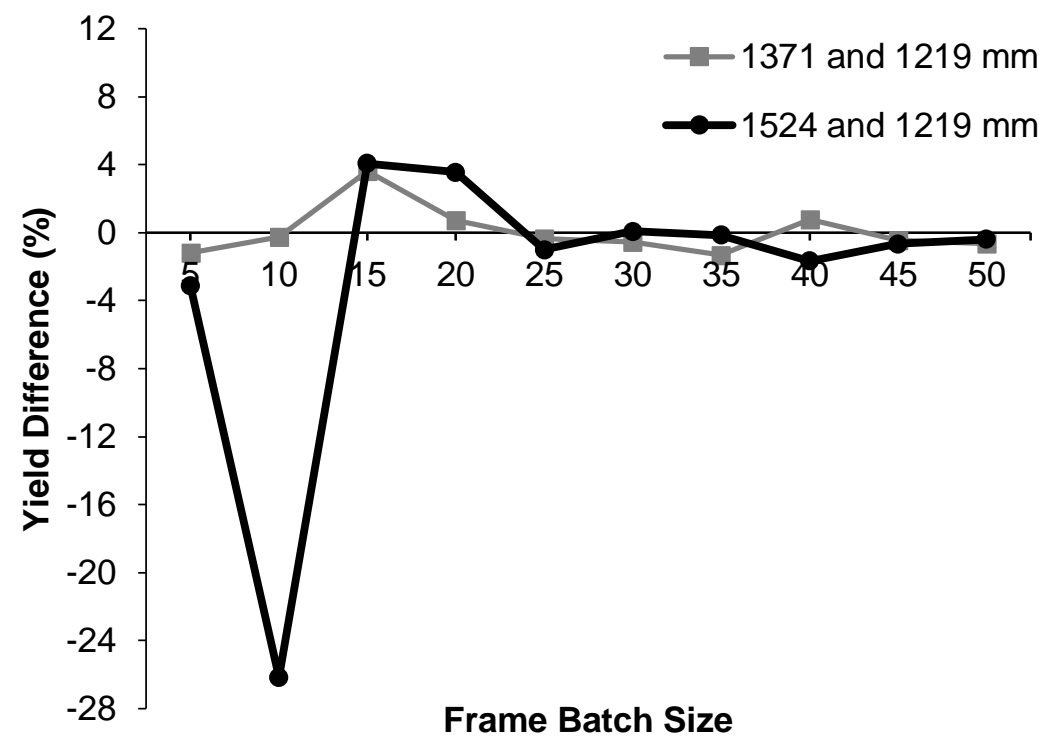

(a)

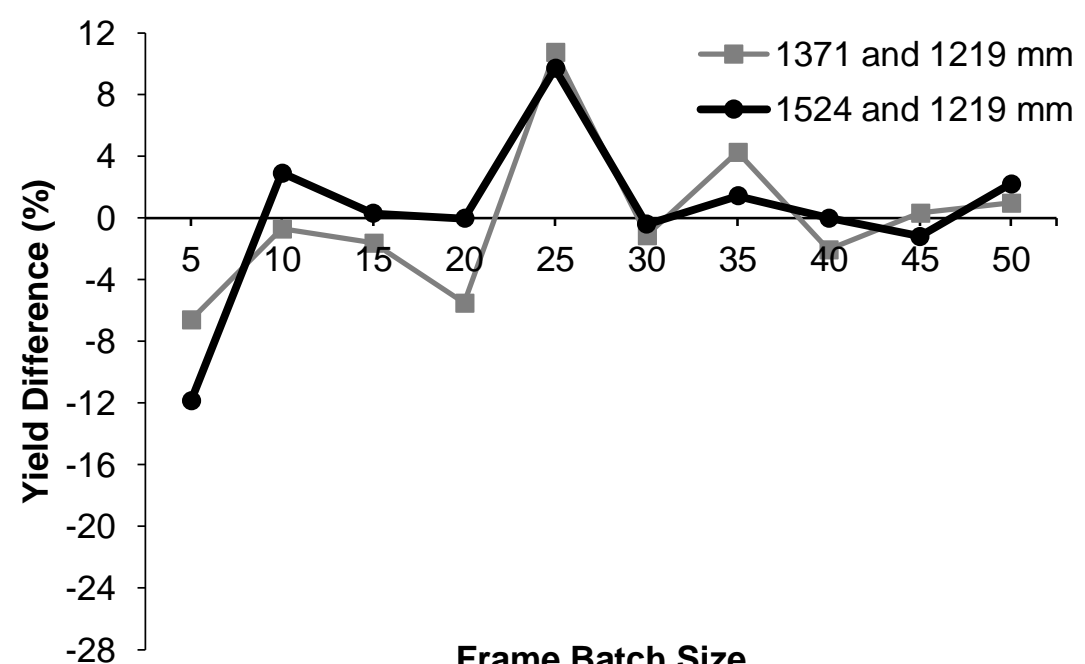

Frame Batch Size

(b)

Fig. 7. Yield differences between the 1371-mm and 1219-mm-wide 19-mm-thick plywood panels and 1524-mm and 1219-mm-wide 19-mm-thick plywood panels for (a) Models I and (b) II, respectively

\section{CONCLUSIONS}

The purpose of the study was to understand how to get better utilization of bioresources in furniture manufacturing process. In this study, the effects of increasing the width of full-size 1219 -mm-wide $\times 2438$-mm-long wood-based composite panel products on the cutting yield of parts for two upholstered frame models were investigated using computer simulation software with an optimization capacity. 
1. The simulation results indicated that increasing the width of the full-size wood-based composite panel products to $1371 \mathrm{~mm}$ and $1524 \mathrm{~mm}$ could yield better material cutting yields than the 1219-mm-wide panel products.

2. The material cutting yield was increased by increasing the panel width that can potentially be offered by panel manufacturers. This can be beneficial to panel and furniture manufacturers by saving money on the panels and manufacturing process.

\section{ACKNOWLEDGMENTS}

This project was partially funded by the Turkish Ministry of National Education. The authors would like to acknowledge Plataine Ltd. (USA) for providing the simulation software.

\section{REFERENCES CITED}

Annamalai, S. (2003). An Investigation of High Speed Machining on CNC Routers Used for Upholstered Furniture Manufacturing, Master's Thesis, North Carolina State University, Raleigh, NC.

APA (1997a). Bassett Furniture: Plywood Furniture Frame Innovations (Form No. X150), American Plywood Association, Tacoma, WA.

APA (1997b). Rowe Furniture: Plywood to Last a Lifetime (Form No. X155), American Plywood Association, Tacoma, WA.

APA (2001). Upholstered Furniture Frames (Form No. B625), American Plywood Association, Tacoma, WA.

Konukcu, A. C. (2014). Improvement of Upholstery Furniture Manufacturing Through Efficient Material Utilization for CNC Layout, Master's Thesis, Mississippi State University, Starkville, MS.

Park, K. S., and Kim, S. H. (1998). "Artificial intelligence approaches to determination of CNC machining parameters in manufacturing: A review," Artif. Intell. Eng. 12(1-2), 127-134. DOI: 10.1016/S0954-1810(97)00011-3

Wiedenbeck, J., and Parsons, J. (2010). "Digital technology use by companies in the furniture, cabinet, architectural millwork, and related industries," Forest Prod. J. 60(1), 78-85. DOI: 10.13073/0015-7473-60.1.78

Youngs, R. L. (1994). "La recherche sur l'utilisation des produits forestiers: La technologie au service d'une exploitation rationnelle [Forest products utilization research: Providing technology for wise use]," Unasylva 45(2), 38-45.

Article submitted: December 4, 2018; Peer review completed: March 23, 2019; Revised version received: March 26, 2-019; Accepted: March 28, 2019; Published: April 5, 2019. DOI: $10.15376 /$ biores.14.2.4181-4193 